\title{
Establishment of Reference Interval for TSH in Pregnant Georgian Women
}

\author{
Peshkova $T^{1}$, Giorgadze $\mathbf{E}^{2}$, Uchava $\mathbf{L}^{3}$, Kamashidze $\mathbf{K}^{4}$ \\ ${ }^{1}$ Dr. Tamar Peshkova, MD, PhD student, Department of Endocrinology, ${ }^{2}$ Dr. Elene Giorgadze, Professor, Department of \\ Endocrinology, ${ }^{3}$ Dr. Lasha Uchava, MD, PhD, Department of Endocrinology, ${ }^{4}$ Dr. Koba Kamashidze, MD, Batumi \\ Maternity House, Batumi, Georgia. ${ }^{1,2,3}$ Authors are affiliated with Ivane Javakhishvili Tbilisi State University and \\ National Institute of Endocrinology, Tbilisi, Georgia.
}

Address for correspondence: Dr. Tamar Peshkova, Email: tampesh@mail.ru

\begin{abstract}
Introduction: Maternal thyroid dysfunction has been associated with variety of adverse maternal and fetal outcomes. Due to many physiological changes during pregnancy, interpretation of thyroid function tests needs trimester-specific reference intervals for a specific population. Aim of this study was to determine the second trimester-specific reference interval for thyroid-stimulating hormone (TSH) in healthy pregnant Georgian women. Methods: 2876 pregnant women were admitted to Batumi Maternity House (BMH) from January 2009 to December 2011 for second trimester routine prenatal examination, including TSH screening. Standardized information regarding thyroidal, obstetric and general medical status of women was collected. The reference interval for TSH, based on 2.5th and 97.5th percentiles, was calculated from thyroid dysfunction risk free pregnant women. Results: Derived reference interval for TSH in the second trimester of pregnancy was $0.21-4.1 \mathrm{mIU} / \mathrm{L}$ and it was significantly different from the reference intervals recommended by American Thyroid Association (ATA) and the reference interval provided by manufacturer for non-pregnant adults. Conclusion: We calculated clinically relevant trimester-specific reference interval for TSH in order to facilitate detection and improve management of thyroid dysfunction in Georgian pregnant women.
\end{abstract}

Keywords: Pregnancy, Reference interval, Second trimester, TSH

\section{Introduction}

Over the last twenty years a major expansion of our knowledge regarding the role of thyroid function during pregnancy has taken place. Thyroid hormones are crucial in fetal development [1]. Maternal thyroid disorders, particularly hypothyroidism, can lead to obstetric complications and cause adverse effects on cognitive and neurological development of the fetus [2, $3,4]$. Appropriate detection of thyroid dysfunction and prompt interventions improve maternal-fetal prognosis [5]. Hormonal changes and increased metabolic demand occurring during pregnancy result in profound and complex effects on thyroid function, and therefore significantly affect the interpretation of thyroid function tests $[6,7]$. For this reason, formation and application of reliable gestational specific reference interval from the pregnant population with minimal risk for thyroid dysfunction is of utmost necessity [8]. Although several

Manuscript received: $2^{\text {th }}$ July 2015

Reviewed: $14^{\text {th }}$ July 2015

Author Corrected: $24^{\text {th }}$ July 2015

Accepted for Publication: $7^{\text {th }}$ Aug 2015 studies are available from different regions of the world [9-18], results are inconsistent, due to differences in ethnicity, iodine status, laboratory assay method and rigor for selection of the reference population. Considering the lack of data regarding thyroid hormones specific reference intervals in pregnant Georgian women, we carried out this study to determine laboratory and geography-specific reference interval for $\mathrm{TSH}$ in healthy Georgian pregnant women.

\section{Material and Methods}

This retrospective cross-sectional study was conducted by the National Institute of Endocrinology (Tbilisi, Georgia) in collaboration with Obstetrics and Gynecology outpatient department of $\mathrm{BMH}$, which is a primary care provider for pregnant women from different parts of Autonomous Republic of Adjara (Western Georgia).

We used data from medical records during pregnancy and birth of 2876 pregnant women who had undergone 
routine prenatal examination and $\mathrm{TSH}$ screening in the second trimester of pregnancy (between 16-20 weeks of gestation) in BMH from January 2009 to December 2011. Standardized information including demographic data, thyroidal, obstetric-gynecological and general medical status was collected and the database was created. From this entire population 1351 women were available with complete information (study population).

Reference population was selected in accordance with the recommendations of National Academy of Clinical Biochemistry (NACB) [8], excluding women with a family or personal history of thyroid dysfunction, visible or palpable goiter, any kind of thyroid operations, use of thyroid medications, evidence for autoimmune thyroid disease. In addition, women with multiple or complicated pregnancies and deliveries, with a past history of spontaneous abortions were also removed from the study population. The values of TSH from established reference population were used to derive reference interval. The study protocol was approved by the ethical committee of the National Institute of Endocrinology according to the Declaration of Helsinki.

The TSH test was performed by Enzyme-Linked Immunosorbent Assay (ELISA) technique, using a Humareader single machine and reagent kits from Human diagnostics (Wiesbaden, Germany). Laboratory procedures, including calibration and internal quality control were as per instructions from the manufacturer. The proposed reference intervals of the standard kit for the ELISA method for TSH in this study was 0.4-5.0 mIU/L.

The reference intervals of TSH from reference population were calculated according to the recommendation of NACB (8): in view of the non- normal distribution of TSH results, the TSH measurements were first transformed to $\log \mathrm{TSH}$ and 2.5-97.5 percentiles of the inverse $\log$ TSH were determined as the reference interval of second trimester of pregnancy. Categorical variables were expressed as frequency and percentage. Chi-square analyses were used to examine associations between categorical variables. All P values below 0.05 were considered statistically significant. Data were analyzed by SPSS 18 (SPSS Inc., Chicago, IL, USA).

\section{Results}

The age of the 1351 women (study population) ranged from 15 to 45 years (mean $24.8 \pm 5.26$ ), of which 294 $(21.8 \%)$ were under 20 years, $856(63.4 \%)$ between 20 and 30 years and $201(14.8 \%)$ over 30 years. The pregnancy order ranged from 1 to 7 , with a median of 2 , and for 839 women $(62.1 \%)$ this was their first pregnancy. History of spontaneous abortions and thyroid illness in the family were present in 166 $(12.3 \%)$ and $89(6.5 \%)$ women, respectively. Clinical examination showed goiter in $243(17.9 \%)$. At the time of TSH analysis, the gestational age determined by last menstrual period and ultrasound ranged from 16-20 weeks.

After applying aforementioned exclusion criteria, 764 women were excluded from the study population, resulting to a final population of 587 women used to determine reference intervals for TSH for the second trimester of pregnancy (Figure 1). Selected reference population was adequate for the statistical study according to the NACB criteria [8]. Mean age of women was $24.7 \pm 4.9$ years. The majority of mothers were of Georgian origin (92.3\%) residing in the region for more than 10 years.

Figure 1: Flow diagram of the study process for the determination of the reference population

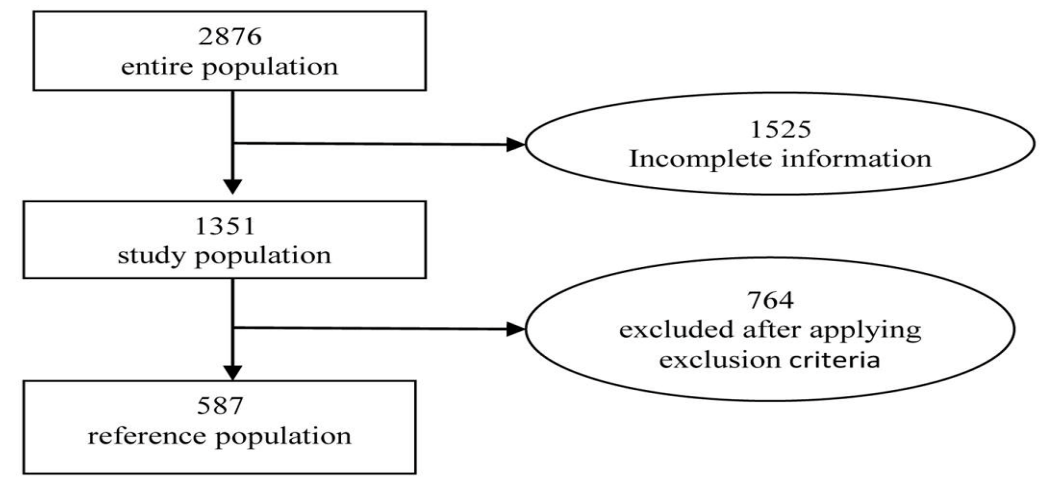


The distribution of TSH values in reference population is shown in figure 2.

Figure 2: TSH distribution in reference population $(n=587)$

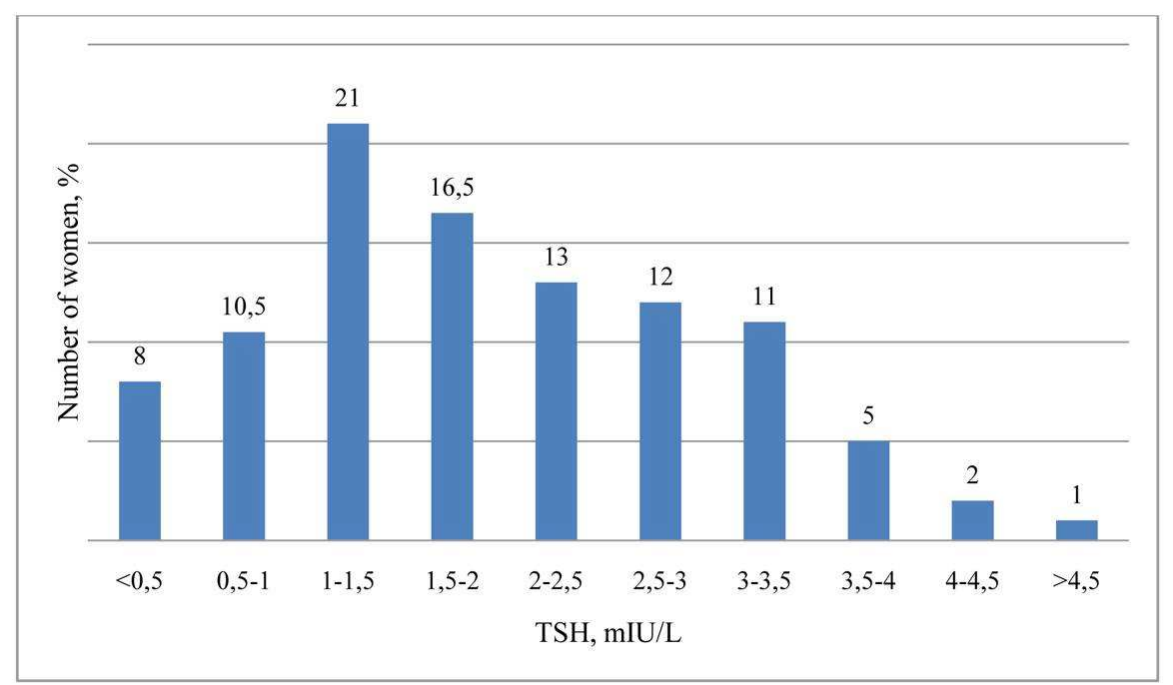

Additionally, medians, the $2.5^{\text {th }}$ and $97.5^{\text {th }}$ percentiles for serum TSH by gestational weeks (16-20 weeks) and for whole second trimester is shown in Table 1.

Table 1: Median, $2.5^{\text {th }}$ and $97.5^{\text {th }}$ percentiles for TSH by gestational weeks and for the whole second trimester

\begin{tabular}{|l|l|l|l|l|}
\hline \multirow{2}{*}{ Gestational week } & \multirow{2}{*}{} & \multicolumn{2}{|l|}{ TSH mIU/L } & $\mathbf{2 7 . 5}^{\text {th }} \boldsymbol{\%}^{\text {ile }}$ \\
\cline { 3 - 5 } & & Median & 0.19 & 4.13 \\
\hline $16-17$ & 146 & 1.83 & 0.21 & 4.07 \\
\hline $17-18$ & 135 & 1.8 & 0.2 & 4.15 \\
\hline $18-19$ & 157 & 1.84 & 0.24 & 4.22 \\
\hline $19-20$ & 149 & 1.89 & 0.21 & 4.1 \\
\hline Whole 2nd trimester & 587 & 1.8 & \\
\hline
\end{tabular}

According to our results, the second trimester specific reference interval of serum TSH for the whole reference group was 0.21-4.1 mIU/L. Derived reference interval was used to interpret TSH results (e.g. 'high'=above 97.5 ${ }^{\text {th }}$ percentile, 'normal'=within $2.5^{\text {th }}$ to $97.5^{\text {th }}$ percentile, and 'low'=below $2.5^{\text {th }}$ percentile) and then was compared with the ATA recommended standards and the reference intervals for non-pregnant women provided by the manufacturer kit. As a result, Table 2 which is given below reflects the percentage of potentially misclassified women in that case if nonpregnant reference intervals and ATA recommended standards are used.

Table 2: The percentage of potentially misclassified women if the manufacturer's, ATA recommended and the derived reference intervals were used

\begin{tabular}{|l|l|l|l|}
\hline Reference interval & Low TSH,n (\%) & Normal TSH,n (\%) & High TSH,n (\%) \\
\hline Manufacturer (0.4-5.0 mIU/L) & $62(4.6)$ & $1210(89.6)$ & $79(5.8) *$ \\
\hline ATA (0.2-3.0 mIU/L) & $16(1.2)$ & $1021(75.6)$ & $314(23.2) \dagger$ \\
\hline Derived (0.21-4.1 mIU/L) & $18(1.3)$ & $1186(87.8)$ & $147(10.9)$ \\
\hline
\end{tabular}

$* \mathrm{p}<0,0001$ in comparison to derived $\uparrow \mathrm{p}<0,0001$ in comparison to derived

Figure 2: TSH distribution in reference population $(\mathrm{n}=587)$ 


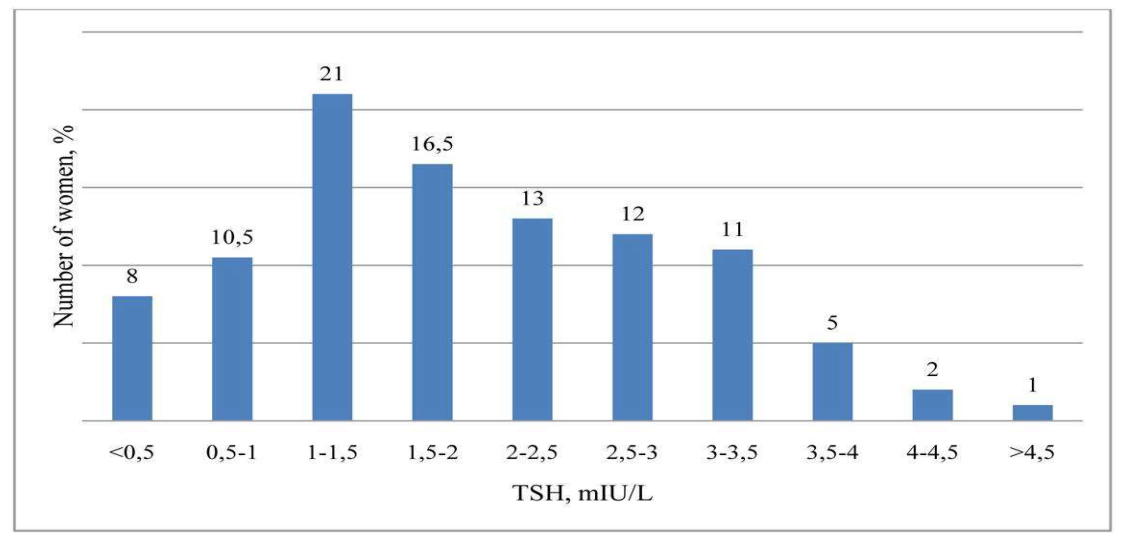

Additionally, the comparison of derived reference interval with the second trimester-specific reference intervals for TSH reported worldwide [13-16] is presented in Table 3.

Table 3: Summary of worldwide studies reporting second trimester specific reference intervals for TSH during pregnancy

\begin{tabular}{|l|l|l|l|l|}
\hline Study & Country & Sample size & Percentiles used & TSH reference intervals \\
\hline Soldin et al. & USA & 83 & $2.5^{\text {th }}-97.5^{\text {th }}$ & $0.46-2.95$ \\
\hline Stricker et al. & Switzerland & 528 & $2.5^{\text {th }}-97.5^{\text {th }}$ & $0.31-2.9$ \\
\hline Marwaha et al. & India & 137 & $5^{\text {th }}-95^{\text {th }}$ & $0.43-5.78$ \\
\hline Bocos-Terraz et al. & Spain & 243 & $2.5^{\text {th }}-97.5^{\text {th }}$ & $0.12-2.64$ \\
\hline Yan et al. & China & 168 & $2.5^{\text {th }}-97.5^{\text {th }}$ & $0.47-4.54$ \\
\hline Current study & Georgia & 587 & $2.5^{\text {th }}-97.5^{\text {th }}$ & $0.21-4.1$ \\
\hline
\end{tabular}

\section{Discussion}

Thyroid dysfunction is one of the most common disorders in pregnant women. It harmfully affects the health of pregnant women and their fetuses [19]. Since the fetus does not completely establish its own thyroid functions until 20 weeks of pregnancy, fetal thyroid hormones are derived mainly from the mother in early pregnancy and their deficiency may impair future neuropsychological development of the fetus [4, 20]. Thus, the identification of thyroid disorders during pregnancy has attracted increased interest from researchers in recent years [21].

TSH is the most sensitive marker of thyroid dysfunction and is recommended as the first-line screening variable in determining thyroid dysfunction in pregnancy [8, 19]. In view of the alterations of $\mathrm{TSH}$ during pregnancy, establishing gestational-specific reference interval for this hormone is indispensable [7, 8]. Guidelines from the American Thyroid Association (ATA) suggest that trimester-specific reference intervals for TSH should be used in every population [7].
Several studies from different countries have attempted to create trimester-specific reference interval for TSH among pregnant women, with inconsistent results perhaps reflecting differences in ethnic background, maternal iodine status, assessment of reference population, and method of analysis used among studies. Black and Asian women have TSH values that are on average $0.4 \mathrm{mIU} / \mathrm{L}$ lower than in white women [22, 23]. Accordingly, pregnant women whose origin is Turkish, Moroccan and Surinamese, have TSH values 0.2-0.3 $\mathrm{mIU} / \mathrm{L}$ lower than Dutch women, though their country of residence is the Netherlands [24]. No relevant studies have been conducted with Georgian women. Our study represents the first study performed in Adjara - Western Georgia, an area of mild to moderate iodine deficiency, located on the eastern end of the Black Sea and extended to the mountains (2000-2500 m above sea level). Iodine deficiency disorders (IDD) were endemic for this region secondary to low iodine levels in water and soil. With the passage of the 2005 law banning the import and sale of non-iodized salt, Georgia met the primary World Health Organization for IDD elimination [25].

The present study provides reference interval for the TSH during the second trimester of pregnancy. From an epidemiological point of view, investigated population 
was ethnically homogenous. In determining the TSH reference interval, it has been customary to logtransform the data because TSH values were not normally distributed. Reference interval based on $2.5^{\text {th }}$ and $97.5^{\text {th }}$ percentiles for TSH in pregnant Georgian women was $0.21-4.1 \mathrm{mIU} / \mathrm{L}$. No definite trend was seen by analysis of the median serum TSH concentration across 16-20 weeks of gestation.

The major discrepancy in TSH reference values in our data compared with other reports mainly exists in the TSH upper reference limit, which in our study is relatively higher than that reported in other studies (Table 2) and ATA recommended standards (3.0 mIU/L for the second trimester), whereas it is significantly lower from those reported by the assay manufacturer for non-pregnant women.

The reference interval of TSH as supplied by the kit manufacturer for non-pregnant adult was 0.4$5.0 \mathrm{mIU} / \mathrm{L}$. Before our study, these values were considered for the determination of thyroid disorders in pregnancy in our laboratory. When this non-pregnant reference interval was used to diagnose thyroid disorders an appreciable number of pregnant women escaped the diagnosis of hypothyroidism - $5.1 \%$ pregnant women in their second trimester of pregnancy.

Data from our study showed an increase of subjects with increased TSH from $10.9 \%$ to $23.2 \%$ when the upper limit was changed from 4.1 to $3.0 \mathrm{mIU} / \mathrm{L}$ (ATA recommended). Consequently, use of an upper reference limit of $3.0 \mathrm{mIU} / \mathrm{L}$ instead of $4.1 \mathrm{mIU} / \mathrm{L}$ for TSH will result in an additional $12.3 \%$ of women in the 2nd trimester being classified as abnormal. As it is our preliminary study, the next investigation will show the clinical significance of the above mentioned discrepancy.

\section{Conclusion}

We established gestational specific reference interval for TSH in pregnant Georgian women. Results of the present study suggest that the upper limit of normal TSH for the Georgian pregnant women would be 4.1 $\mathrm{mIU} / \mathrm{L}$ for the second trimester, a limit higher than traditionally ATA recommended standards and lower then non-pregnant reference interval. Observed differences among the worldwide studies reported provide further evidence of importance of applying laboratory- and population-specific reference interval in order to avoid misclassification of pregnant women with thyroid dysfunction

\section{Funding: Nil, Conflict of interest: Nil, Permission from IRB: Yes}

\section{References}

1. de Escobar GM, Obregón MJ, del Rey FE. Maternal thyroid hormones early in pregnancy and fetal brain development. Best Pract Res Clin Endocrinol Metab. 2004 Jun; 18(2): 225-48.

2. Casey BM, Dashe JS, Wells CE, McIntire DD, Byrd $\mathrm{W}$, Leveno KJ, et al. Subclinical hypothyroidism and pregnancy outcomes. Obstet Gynecol. 2005 Feb;105(2):239-45.

3. Allan WC, Haddow JE, Palomaki GE, Williams JR, Mitchell ML, Hermos RJ, et al. Maternal thyroid deficiency and pregnancy complications: implications for population screening. J Med Screen. 2000;7(3):127130.

4. Haddow JE, Palomaki GE, Allan WC, Williams JR, Knight GJ, Gagnon J, et al. Maternal thyroid deficiency during pregnancy and subsequent neuropsychological development of the child. N Engl J Med.1999 Aug 19;341(8):549-55.

5. Lazarus JH. "Screening for thyroid dysfunction in pregnancy: is it worthwhile?" Journal of Thyroid Research, vol. 2011, Article ID 397012, 4 pages, 2011.

6. Glinoer D. The regulation of thyroid function in pregnancy: pathways of endocrine adaptation from physiology to pathology. Endocr Rev 1997 Jun;18(3):404-33.

7. Stagnaro-Green A, Abalovich M, Alexander E, Azizi F, Mestman J, Negro R, et al. Guidelines of the American Thyroid Association for the diagnosis and management of thyroid disease during pregnancy and postpartum. Thyroid. 2011 Oct; 21(10): 1081-1125.

8. Baloch Z, Carayon P, Conte-Devolx B, Demers LM, Feldt-Rasmussen U, Henry JF, et al. Laboratory medicine practice guidelines. Laboratory support for the diagnosis and monitoring of thyroid disease. Thyroid. 2003 Jan;13(1):3-126.

9. Gilbert RM, Hadlow NC, Walsh JP, et al. Assessment of thyroid function during pregnancy: first- 
trimester (weeks 9-13) reference intervals derived from Western Australian women. Med J Aust.2008 Sep $1 ; 189(5): 250-3$.

10. Cotzias C, Wong SJ, Taylor E, et al. A study to establish gestation-specific reference intervals for thyroid function tests in normal singleton pregnancy. Eur J Obstet Gynecol Reprod Biol. 2008:137:61-6.

11. Springer D, Zima T, Limanova Z. Reference intervals in evaluation of maternal thyroid function during the first trimester of pregnancy. Eur $\mathbf{J}$ Endocrinol. 2009 May;160(5):791-7.

12. Aytan H, Aytan P, Demirtürk F, Çalişkan A, et al First-trimester thyroid hormone reference data in a Turkish pregnant women population living in middle blacksea region. Nobel Medicus Journal. 2014 JanApr,10 (1) 1, 25-29.

13. Soldin OP, Soldin D, Sastoque M. Gestationspecific thyroxine and thyroid stimulating hormone levels in the Unitied States and worldwide. Ther Drug Monit, 2007 Oct; 29(5):553-9.

14. Stricker R, Echenard M, Eberhart R, Chevailler MC, Perez V, Quinn FA, et al. Evaluation of maternal thyroid function during pregnancy: the importance of using gestational age-specific reference intervals. Eur J Endocrinol. 2007 Oct;157(4):509-14.

15. Marwaha RK, Chopra S, Gopalakrishnan S, et al. Establishment of reference range for thyroid hormones in normal pregnant Indian women. BJOG. 2008 Apr;115(5):602-6.

16. Bocos-Terraz JP, Izquierdo-Alvarez S, BancaleroFlores JL, et al. Thyroid hormones according to gestational age in pregnant Spanish women. BMC Res Notes. 2009 Nov 26;2:237.

17. Yan Yu-qin, Dong Zuo-liang, Dong Ling, et al. Trimester -and method-specific reference intervals for thyroid tests in pregnant Chinese women: methodology, euthyroid definition and iodine status can influence the setting of reference intervals. Clinical Endocrinology. 2011 Feb,2, 262-69.

18. La'ulu SL, Roberts WL. Second-trimester reference intervals for thyroid tests: the role of ethnicity. Clin Chem. 2007;53(9):1658-64.

19. Abalovich M, Amino N, Barbour LA, Cobin RH, De Groot LJ, Glinoer D. Management of thyroid dysfunction during pregnancy and postpartum: an Endocrine Society Clinical Practice Guideline. J Clin Endocrinol Metab. 2007 Aug. 92(8 Suppl):S1-47.

20. de Escobar GM., Ares S, Berbel P, Obregón MJ, del Rey FE. The changing role of maternal thyroid hormone in fetal brain development. Semin Perinatol. 2008 Dec;32(6):380-6.

21. Cignini P, Cafà EV, Giorlandino C, Capriglione S, Spata A, Dugo N. Thyroid physiology and common diseases in pregnancy: review of literature. J Prenat Med. 2012 Oct;6(4):64-71.

22. Price A. Obel O. Cresswell J. Catch I. Rutter S. Barik S. Heller SR. Weetman AP. Comparison of thyroid function in pregnant and non-pregnant Asian and western Caucasian women. Clin Chim Acta. 2001 Jun;308(1-2): 91-8.

23. Walker JA, Illions EH, Huddleston JF, Smallridge RC. Racial comparisons of thyroid function and autoimmunity during pregnancy and the postpartum period. Obstet Gynecol. 2005 Dec; 106(6):1365-71.

24. Benhadi N, Wiersinga WM, Reitsma JB, Vrijkotte TG, van der Wal MF, Bonsel GJ. Ethnic differences in $\mathrm{TSH}$ but not in free $\mathrm{T}_{4}$ concentrations or TPO antibodies during pregnancy. Clin Endocrinol (Oxf).2007 Jun;66(6):765-70.

25. Suchdev PS, Jashi M, Sekhniashvili Z, Woodruff BA. Progress toward Eliminating Iodine Deficiency in the Republic of Georgia. Int $J$ Endocrinol Metab 2009;3: 200-207.

\section{How to cite this article?}

Peshkova T, Giorgadze E, Uchava L, Kamashidze K. Establishment of Reference Interval for TSH in Pregnant Georgian Women. Int J Med Res Rev 2015;3(7):748-753. doi: 10.17511/ijmrr.2015.i7.143. 